\title{
联烯酸酯的区域/立体选择性氟芳基化反应
}

\author{
张发光 马军安* \\ (天津大学化学系 天津 300072)
}

\section{Regio- and Stereo-selective Vicinal Fluoroarylation of Allenoates}

\author{
Zhang, Faguang Ma, Jun'an* \\ (Department of Chemistry, Tianjin University, Tianjin 300072)
}

基于不饱和碳一碳双键的双官能团化反应，近年来 引起广泛关注 ${ }^{[1]}$, 其中烯烃的氟芳基化反应可从廉价易 得原料出发, 快速构建具有重要医药应用潜力的含氟分 子, 代表性工作包括马军安 ${ }^{[2]} /$ Gouverneur 等 ${ }^{[3]}$ 发展的氟 环化反应, Heinrich ${ }^{[4]} /$ 汤平平等 ${ }^{[5]}$ 发展的自由基氟芳基化 反应, Toste 等 ${ }^{[6]}$ 发展的四价钯不对称氟芳基化反应等. 尽管如此, 有关联烯化合物的双官能团化反应, 特别是 氟化双官能团化反应仍非常罕见 ${ }^{[7]}$, 是该领域的重要挑 战.

2013 年, Doyle 小组 ${ }^{[8]}$ 报道了首例联烯的氟芳基双 官能团化反应, 以 $\mathrm{Pd}_{2}(\mathrm{dba})_{3}$ 为金属催化剂, $\mathrm{AgF}$ 为亲核 性氟源, 联烯可与钯催化剂及芳基碘苯形成关键烯丙基 钯物种, 随后氟亲核进攻可得到烯丙基氟类产物 (Scheme 1a), 但该反应对联烯底物类型依赖性较强, 且 区域选择性较差，限制了其在合成中的实际应用. 因此 一种更加高效高选择性的联烯氟芳基化反应仍亟待发
展.

最近, 南京工业大学先进化学制造研究院冯超课题 组 ${ }^{[9]}$ 报道了联烯酸酯与芳基重氮盐及三乙胺三氢氟酸盐 的一锅化学转化, 以 $\mathrm{Ph}_{3} \mathrm{AuCl}$ 为金属催化剂, 在可见光 促进条件下可顺利实现一系列 $\beta$-氟烷基肉桂酸酯类化 合物的高区域选择性和立体选择性合成(Scheme 1b), 反应条件温和, 底物兼容性广泛, 为联烯的精准双官能 团化提供了新的方法和思路.

在该工作中, 他们发现使用蓝光照射可以明显提高 反应收率，且联烯底物中的酯基对反应成功起到至关重 要的作用，如以氧基或砜基等替代酯基时，反应几乎没 有产物. 该反应对各类联烯酸酯与芳基重氮盐均具有广 泛的底物适用性(Scheme 2), 共计得到 62 个 $\beta$-氟烷基肉 桂酸酯产物, 收率最高可达 $91 \%$, 且可用于天然产物薄 荷醇、维生素 $\mathrm{E}$ 及雌酮等衍生物的修饰.

(a)
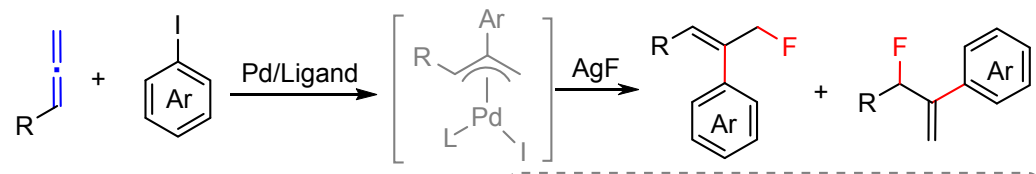

Doyle, 2013, palladium catalysis

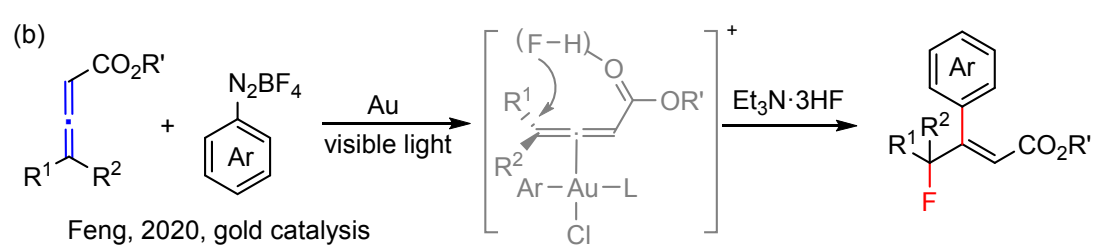

图式 1 联烯的氟芳基化反应

Scheme 1 Fluoroarylation reactions of allenes

*Corresponding author. E-mail: majun_an68@tju.edu.cn. Published online March 18, 2020. 

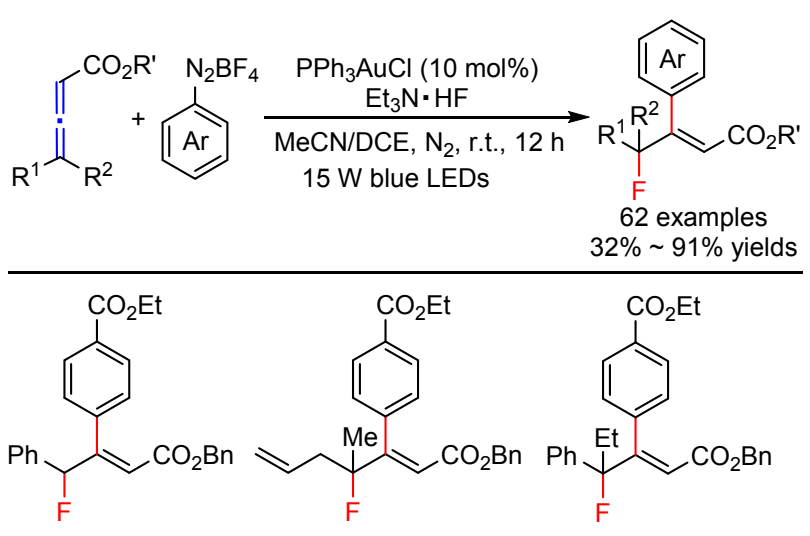

$70 \%$ yield

$50 \%$ yield

$70 \%$ yield<smiles>CCOC(=O)c1ccc(C(=CC(=O)OCc2ccccc2)C2(F)CCOCC2)cc1</smiles>

$61 \%$ yield<smiles>CC(C)(F)/C=C(\C(=O)OCc1ccccc1)c1ccc2c(c1)OCO2</smiles>

$73 \%$ yield<smiles>Cc1cc(=O)oc2cc(/C(=C/C(=O)OCc3ccccc3)C(C)(C)F)ccc12</smiles><smiles>CC(C)[C@@H]1CC[C@@H](C)C[C@H]1OC(=O)c1ccc(/C(=C\C(=O)OCc2ccccc2)C(C)(C)F)cc1</smiles>

$66 \%$ yield

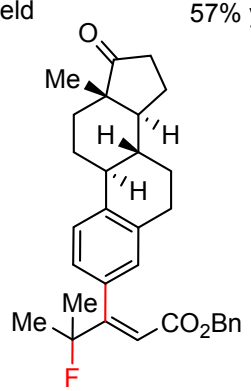

$55 \%$ yield
图式 2 金催化的联烯酸酯 $\beta, \gamma$-氟芳基化反应

Scheme 2 Au-Catalyzed $\beta, \gamma$-vicinal fluoroarylation reactions of allenoates

在机理实验中，使用单独制备的三价芳基金中间体 为原料进行反应(Scheme 3a), 仍可以 $38 \%$ 的收率得到目 标产物, 表明该反应很可能经历三价芳基金路径 ${ }^{[10]}$. 采 用对映体过量值 $(e e)$ 为 $65 \%$ 的联烯酸酯在标准条件下进 行反应(Scheme $3 \mathrm{~b}$ ), 以 $53 \%$ 的产率和 $43 \%$ 的 ee 值得到 相应手性产物, 手性传递过程中的立体化学损失表明, 高价金中间体对于联烯的活化与亲核氟进攻不历经完 全协同模式. 在此基础上, 他们提出了该反应的可能机 理(Scheme 3c): 在可见光促进下金催化剂 $\mathrm{Au}(\mathrm{I})$ 与芳基 重氮盐进行氧化加成得到三价金中间体 II, 其随后与联 烯酸酯进行配位形成中间体 III, 与此同时氢氟酸借助 与酯基的氢键作用选择性地从酯基一侧接近被 $\mathrm{Ar}-\mathrm{Au}(\mathrm{III})$ 活化的双键, 进行亲核加成后得到中间体 $\mathbf{V}$, $\mathrm{V}$ 发生双键构型异构生成中间体 VI, 最后经还原消除 得到产物并释放出活性催化剂.

总之, 冯超课题组的工作解决了联烯酸酯的区域/ 立体选择性氟芳基化反应, 为一系列 $\beta$-氟烷基肉桂酸酯

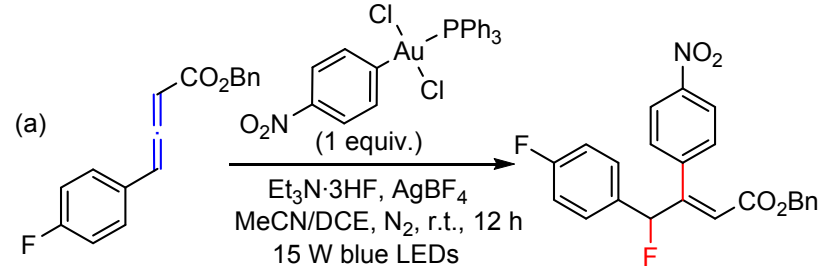
$38 \%$ yield

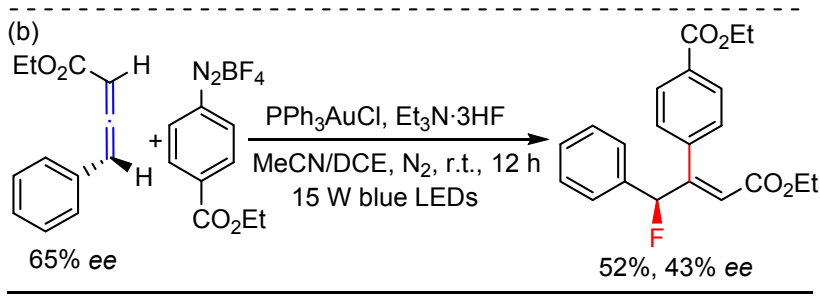

(c)<smiles>[R20]C/C=C(/[R])C[3H]</smiles>

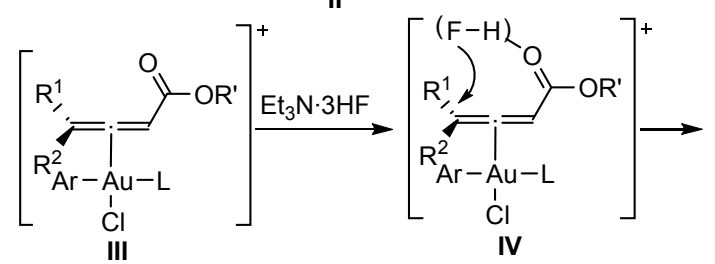

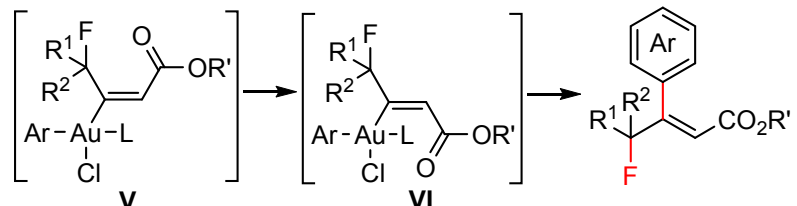

图式 3 金催化的联烯酸酯氟芳基化反应机理研究 Scheme 3 Mechanistic studies on the Au-catalyzed $\beta, \gamma$-vicinal fluoroarylation reactions of allenoates

化合物的合成提供了新方法，对于进一步拓展丰富联烯 双官能团化反应的化学空间具有重要启发意义与应用 价值，其中该策略在手性含氟化合物合成方面仍具有很 大的发展空间.

\section{References}

[1] Yin, G.; Mu, X.; Liu, G. Acc. Chem. Res. 2016, 49, 2413.

[2] Nie, J.; Zhu, H.-W.; Cui, H.-F.; Hua, M.-Q.; Ma, J.-A. Org. Lett. 2007, 9, 3053.

[3] Wolstenhulme, J. R.; Rosenqvist, J.; Lozano, O.; Ilupeju, J.; Wurz, N.; Engle, K. M.; Pidgeon, G. W.; Moore, P. R.; Sandford, G.; Gouverneur, V. Angew. Chem., Int. Ed. 2013, 52, 9796.

[4] Kindt, S.; Heinrich, M. R. Chem.-Eur. J. 2014, 20, 15344.

[5] Guo, R.; Yang, H.; Tang, P. Chem. Commun. 2015, 51, 8829.

[6] Talbot, E. P. A.; Fernandes, T. de A.; McKenna, J. M.; Toste, F. D. J. Am. Chem. Soc. 2014, 136, 4101.

[7] Zhou, C.; Li, J.; Lu, B.; Fu, C.; Ma, S. Org. Lett. 2008, 10, 581.

[8] Braun, M.-G.; Katcher, M. H.; Doyle, A. G. Chem. Sci. 2013, 4, 1216.

[9] Tang, H.-J.; Zhang, X.; Zhang, Y.-F.; Feng, C. Angew. Chem., Int Ed. 2020, 59, 5242 .

[10] Kim, S.; Toste, F. D. J. Am. Chem. Soc. 2019, 141, 4308. 